\title{
An Explosive Range Model Based on the Gas Composition, Temperature, and Pressure during Air Drilling
}

\author{
Xiangyu Fan, ${ }^{1}$ Ping Zhang, ${ }^{2}$ Qiangui Zhang, ${ }^{1}$ Bozhong Yang, ${ }^{3}$ Bo Wang, ${ }^{2}$ and Wen Nie ${ }^{4}$ \\ ${ }^{1}$ School of Oil \& Natural Gas Engineering, Southwest Petroleum University, Chengdu, Sichuan 610500, China \\ ${ }^{2}$ Shengli Petroleum Engineering Limited Company, SINOPEC, Hekou, Shandong 257000, China \\ ${ }^{3}$ CCDC Drilling \& Production Technology Research Institute, Guanghan, Sichuan 618300, China \\ ${ }^{4}$ State Key Laboratory of Coal Mine Disaster Dynamics and Control, Chongqing University, Chongqing 400044, China
}

Correspondence should be addressed to Wen Nie; niewen1026@gmail.com

Received 14 September 2015; Revised 21 December 2015; Accepted 24 December 2015

Academic Editor: Sergey A. Suslov

Copyright (c) 2016 Xiangyu Fan et al. This is an open access article distributed under the Creative Commons Attribution License, which permits unrestricted use, distribution, and reproduction in any medium, provided the original work is properly cited.

\begin{abstract}
Air drilling is low cost and effectively improves the penetration rate and causes minimal damage to liquid-sensitive pay zones. However, there is a potential downhole explosion when combustible gas mixed with drilling fluid reaches the combustible condition. In this paper, based on the underground combustion mechanism, an explosive range calculation model is established. This model couples the state equation and the empirical formula method, which considers the inert gas content, pressure, mixed gas component, and temperature. The result shows that increase of the inert gas content narrows the explosive range, while increase of the gas temperature and pressure improves the explosive range. A case in Chongqing, China, is used to validate the explosive range calculation model.
\end{abstract}

\section{Introduction}

Air drilling technology takes the compressed air as the flow medium and uses this continuous air flow to cool the bit and take the rock debris out of the well [1]. Its advantages include low cost and effective penetration rate and minimal damage to liquid-sensitive pay zones [2]. However, during the air drilling, the drilling air may meet the gas in the oil gas stratum. If the mixed gas reaches the combustion condition, an explosion will probably occur, causing accidents such as burning out the drilling tools and ruining the wells [3, 4]. Gas content, temperature, and pressure are regarded as the main factors affecting the explosion range [5-7]. In our study an explosive range calculation model is developed for estimation of the air drilling explosive range. This model couples the state equation and the empirical formula method, which considers the inert gas content, pressure, mixed gas component, and temperature affecting the explosive range.

\section{Calculation Model of Explosive Range}

The lower limit of explosion refers to the lowest concentration of combustible gas mixed air for the flame to spread, represented by $L$; the upper limit of explosion refers to the highest concentration of combustible gas mixed air for the flame to spread, represented by $U$. The range of concentration between $L$ and $U$ is called the explosive range $[8,9]$. The explosive range is an important judgment for downhole explosion. The model considers the three factors of the inert gas content, temperature, and gas pressure affecting the explosive range, which is calculated by the empirical formula and state equation. Firstly, the gas composition, temperature, and pressure are inserted separately into the empirical formula calculation module and state equation calculation module. In particular, the Lee-Kesler equation is substituted into the state equation. Then the model can directly select the corresponding $Z^{0}$ and $Z^{1}$ to calculate. If the inert gas is included, the effect of inert gas on the explosive 


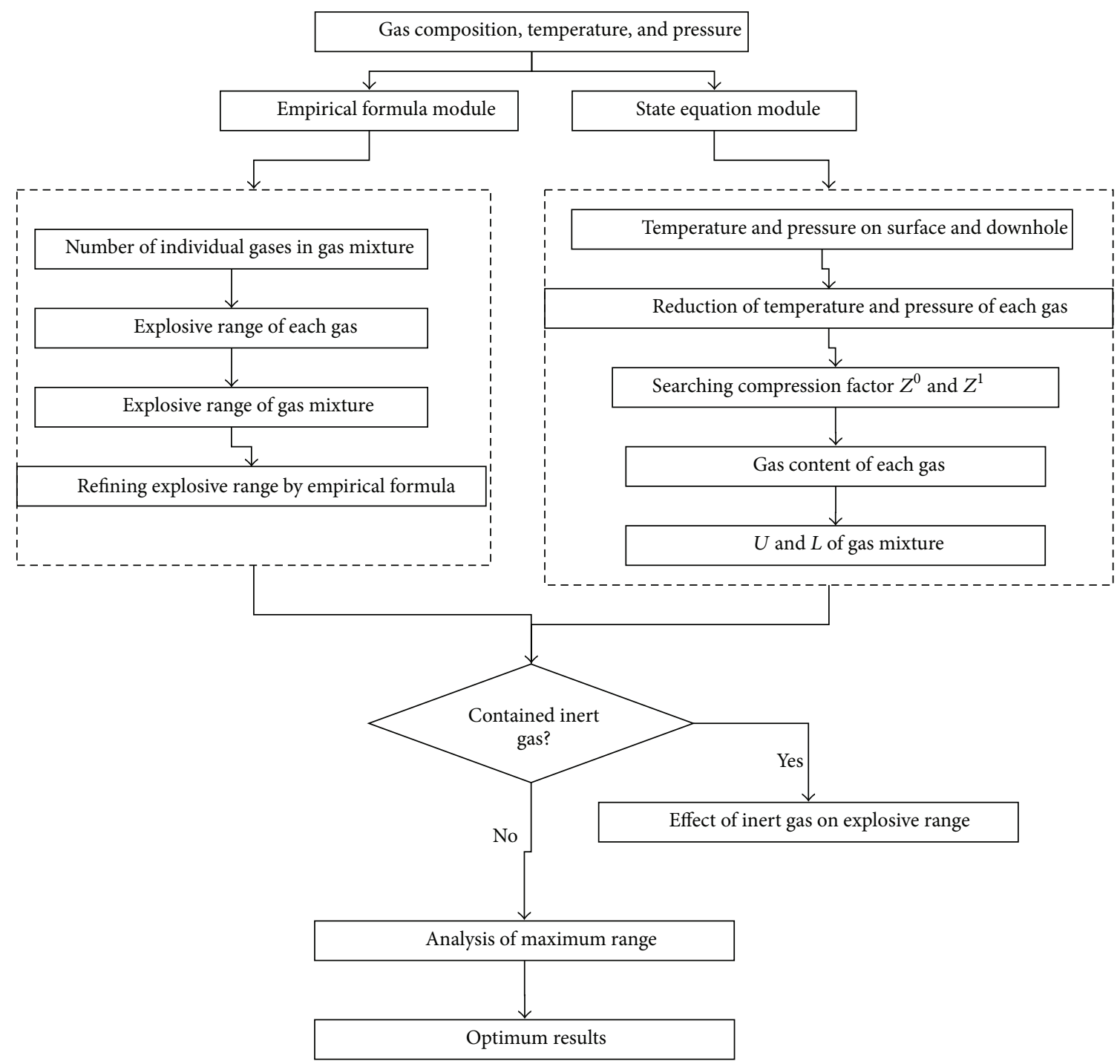

FIGURE 1: Working principle of the calculation of explosive range.

range will be evaluated. Finally, after analysis of the maximum range based on the two methods (the union of two ranges), the model selects an optimum result as the output. The working principle of the calculation of the explosive range is shown in Figure 1.

2.1. Assumption Terms. This program mainly considers the influence of gas pressure, temperature, and inert gas on the explosive range. The basic assumptions are as follows:

(1) The reaction proceeds in a closed container, and the temperature remains the same during the reaction.

(2) The temperature and concentration of the reactant in the entire container are isotropic (the speed of the reaction is the same everywhere). The temperature of the reactant remains the same as the surface of the container at the beginning of the reaction.

(3) The combined heat exchanger system through which the air exchanges to the surface does not change with the temperature, gas pressure, and physical properties.

2.2. Calculation of Explosive Range Based on the Ground and Underground Temperature and Gas Pressure. The model considers the effect of the temperature and gas pressure on the explosive range, and the explosive range is calculated by the empirical formula and state equation.

2.2.1. Calculation of Explosive Range Based on the Empirical Formula. During drilling, the underground temperature is usually higher than the ground temperature. Once the ground temperature exceeds $100^{\circ} \mathrm{C}$, the influence of temperature on the explosion is obvious. The limits can be calculated from [6]

$$
\begin{aligned}
& L_{t}=L-8 \times 10^{-4} \times L(t-25), \\
& U_{t}=U+8 \times 10^{-4} \times U(t-25),
\end{aligned}
$$


TABLE 1: Empirical coefficients used in explosive range calculation of single gas.

\begin{tabular}{lcccc}
\hline Empirical coefficient & $a_{1}$ & $a_{2}$ & $b_{1}$ & $b_{2}$ \\
\hline Values & $0.1314-0.1448$ & $0.0103-0.0193$ & $0.0418-0.0686$ & $0.0472-0.0563$ \\
\hline
\end{tabular}

where $L_{t}$ is the lower limit of explosion at $t^{\circ} \mathrm{C}, \%$; $U_{t}$ is the upper limit of blast at $t^{\circ} \mathrm{C}, \%$; $L$ is the upper explosive limit at normal temperature $\left(25^{\circ} \mathrm{C}\right), \%$; $L$ is the lower explosive limit of explosion at normal temperature $\left(25^{\circ} \mathrm{C}\right), \%$; $t$ is the temperature of the combustible gas, ${ }^{\circ} \mathrm{C}$.

In addition, increase of the gas pressure also affects the range of the explosion. Equation (2) can be used to calculate the explosive range of the gas mixture between the normal gas pressure and $21 \mathrm{MPa}$ :

$$
\begin{aligned}
& L_{p}=L+20.6 \times(\lg p+1), \\
& U_{p}=U-0.71 \times(\lg p+1),
\end{aligned}
$$

where $L, U$ are the explosive limits of the gas mixture under atmospheric gas pressure. For the purpose of simplified calculation, the chemical reactions among these combustible gases are ignored. The Le Chatelier rule is used to calculate the upper and lower limit of the gas mixture explosion $[10,11]$ as follows:

$$
\begin{aligned}
L_{h} & =\left(\sum_{i}^{n} \frac{c_{i}}{L_{i}}\right)^{-1} \times 100 \%, \\
U_{h} & =\left(\sum_{i}^{n} \frac{c_{i}}{U_{i}}\right)^{-1} \times 100 \%,
\end{aligned}
$$

where $U_{h}$ and $L_{h}$ are the upper and lower limit of the gas mixture under normal gas pressure and temperature, $\% ; c_{i}$ is the concentration of each individual gas in the gas mixture, $\%, c_{1}+c_{2}+c_{3}+\cdots=100 ; U_{i}$ and $L_{i}$ are the upper and lower limit of each gas, \%; $n$ is percentage of each gas contained in the gas mixture.

For each individual gas, the lower and upper limit of the explosion can be calculated using the carbon number. The calculation formula is as follows [12]:

$$
\begin{aligned}
& L_{x}=\left(a_{1} n_{c}+b_{1}\right)^{-1} \times 100 \%, \\
& U_{x}=\left(a_{2} n_{c}+b_{2}\right)^{-1} \times 100 \%,
\end{aligned}
$$

where $L_{x}$ is the lower limit of explosion of the single gas component, \%; $U_{x}$ is the upper limit of explosion of the single gas component, $\%$, and $x$ is $1,2,3, \ldots ; n_{\mathrm{c}}$ is the carbon number in the chain hydrocarbon molecule; $a_{1}, a_{2}, b_{1}$, and $b_{2}$ are the empirical coefficients. The values are recommended as shown in Table 1.

2.2.2. Calculation of Explosive Range Based on the Gas State Equation. The ideal gas law ignores the force acting between the molecules and the volume of the molecule, which has a relatively obvious error for air drilling. Thus, the compressibility factor $Z$ is introduced to modify the gas state equation [10]:

$$
P V=Z R T,
$$

where $R$ is $8.31 \mathrm{~J} / \mathrm{K} \cdot \mathrm{mol}$. The compressibility factor $Z$ is calculated by the Lee-Kesler equation:

$$
Z=Z^{0}+\omega Z^{1}
$$

where $Z^{0}$ and $Z^{1}$ are the values of subentry of the compressibility factor, which are nondimensional, and $\omega$ is the acentric factor. The acentric factor of each gas can be obtained from the table of Lee-Kesler equation compression factor itemized values [13].

With $T_{r}$ and $P_{r}, Z^{0}$ and $Z^{1}$ can be obtained from the values of the subentry of the compressibility factor from the LeeKesler equation [13]. Equations (7) are used to calculate $T_{r}$ and $P_{r}$ :

$$
\begin{aligned}
& T_{r}=\frac{T}{T_{c}}, \\
& P_{r}=\frac{P}{P_{c}},
\end{aligned}
$$

where $T_{r}$ and $P_{r}$ are the reduced temperature and gas pressure and $T_{c}$ and $P_{c}$ are the critical temperature and pressure of the air.

The actual volume of each gas can be calculated by (6). For the acentric factor of the gas mixture, virtual critical parameters are introduced. Regarding the gas mixture as the pure virtual material, thus, the actual volume of the gas mixture underground can be acquired according to (6).

Virtual critical parameters are as follows:

$$
\begin{aligned}
& T_{p c}=y_{1} T_{c r 1}+y_{2} T_{c r 2}+y_{3} T_{c r 3}+\cdots, \\
& P_{p c}=y_{1} P_{c r 1}+y_{2} P_{c r 2}+y_{3} P_{c r 3}+\cdots .
\end{aligned}
$$

The reduced temperature and pressure of the gas in the mixture are

$$
\begin{aligned}
& T_{p r}=\frac{T}{T_{p c}}, \\
& P_{p r}=\frac{P}{P_{p c}} .
\end{aligned}
$$

The acentric factor of the gas mixture is

$$
\omega=y_{1} \omega_{1}+y_{2} \omega_{2}+y_{3} \omega_{3}+\cdots,
$$

where $T_{p c}$ and $P_{p c}$ are the virtual critical temperature and gas pressure of the mixture; $T_{p r}$ and $P_{p r}$ are the virtual reduced 
temperature and gas pressure; $T_{c r x}, P_{c r x}, \omega_{x}$ are the critical temperature, gas pressure, and the acentric factor of each gas, $x=1,2,3, \ldots ; y_{x}$ is the mole fraction of each gas, $x=$ $1,2,3, \ldots$

Substituting the gas pressure and temperature obtained by using the above approach into (5), the state equation of the gas mixture underground or the single gas is obtained. Considering (11) and (12), the percentage of the individual gas can be calculated.

State equation of the ground is as follows:

$$
P_{s} V_{s}=Z^{s} R T_{s}
$$

State equation of any point in the well is as follows:

$$
P_{d} V_{d}=Z^{d} R T_{d}
$$

where $P_{s}$ and $P_{d}$ are the ground gas pressure and gas pressure in the shaft, $\mathrm{MPa} ; V_{s}$ and $V_{d}$ are the ground volume and volume in the shaft, $\mathrm{g} / \mathrm{cm}^{3} ; Z_{s}$ and $Z_{d}$ are the compressibility factor of the ground and in the shaft; $T_{s}$ and $T_{d}$ are the temperature of the ground and in the shaft, ${ }^{\circ} \mathrm{C}$.

The total volume of the gas mixture is as follows:

$$
V_{d}=\frac{P_{s} Z^{d} V_{s} T_{d}}{P_{d} Z^{s} T_{s}} .
$$

Volume of individual gas is as follows:

$$
V_{x d}=\frac{P_{s} Z^{d}{ }_{x} V_{s} T_{d} y_{x}}{P_{d} Z^{s}{ }_{x} T_{s}} .
$$

Percentage of individual gas in the well is as follows:

$$
\phi_{x}=\frac{V_{x d}}{V_{d}}
$$

where $x$ is the individual gas, $x=1,2,3, \ldots$

Substituting (15) into (3), the explosive range of any point in the shaft can be obtained considering the change of temperature and gas pressure.

\subsection{Calculation of Explosive Range in Consideration of Inert} Gas. An inert gas exists in the combustible gas, meaning that the inert gas molecules participate in the collision but that there is no reaction in the gas mixture. The gas molecules reduce the valid molecule collision in the entire system and consume the kinetic energy of a large amount of activated molecules, which decreases the chemical reaction rate and affects the explosive range of the gas mixture in the well [14]. The calculation formula of the explosive range considering the inert gas is

$$
\begin{aligned}
& L_{m}=\frac{10^{4} L_{h}}{10^{4}-\left(100-L_{h}\right) \alpha}, \\
& U_{m}=\frac{10^{4} U_{h}}{10^{4}-\left(100-U_{h}\right) \alpha},
\end{aligned}
$$

where $L_{m}$ is the lower explosive limit of the gas mixture considering the inert gas, $\%$; $U_{m}$ is the upper explosive limit of the gas mixture considering the inert gas, $\% ; L_{h}$ is the lower explosive limit of the gas mixture without considering the inert gas, $\% ; U_{h}$ is the upper explosive limit of the gas mixture without considering the inert gas, $\%$; $\alpha$ is the volume fraction of the inert gas, $\%, \alpha=\varphi_{\mathrm{CO}_{2}}+\varphi_{\mathrm{N}_{2}}+\varphi_{\mathrm{H}_{2} \mathrm{O}} \cdots$.

It should be pointed out that (16) does not consider the impact of every inert gas.

\subsection{Model Programming}

2.4.1. Programming Language Introduction. The programming of the explosive range model in the well is carried out in the Visual Basic Microsoft 6.0 environment of the Windows system. Visual Basic is a graphical user interface (GUI) programming language, which also fully supports object-oriented programming. In addition, with the aid of visibility programming, Visual Basic provides users with a quick and simple way to develop Windows applications [15].

2.4.2. Programming Introduction. The calculation model of the explosive range in the well realizes the functions of the input of logging data and automatically chooses the compression factor component values $Z^{0}$ and $Z^{1}$. Also, it adopts the empirical formula and state equation to calculate the explosion range under the influence of temperature and pressure (the maximum explosion range of the two methods as the output). The interface of the software is shown in Figure 2. The upper part displays the imported factor component values $Z^{0}$ and $Z^{1}$. The lower left part shows the parameters input from the data logging; the results output is in the lower right part.

\subsubsection{Highlights of Program}

(1) Straightforward Parameter Inputting. In Figure 2, after inputting the logging data of the gas composition content, the model calculates the explosion limits of the individual components and the gas mixture under atmospheric pressure with (3) and (6). Next, after inputting the hole temperatures and the pressures of the ground and bottom, with (5)-(15) the refined gas compositions are calculated. By combining them into (3), the explosion range considering the effects of temperature and pressure is calculated by the equation method.

(2) The Prestorage of the Values of Subentry of the Compressibility Factor. In the process of the state equation method, the very time-consuming step is to use the parameters $Z^{0}$ and $Z^{1}$ in the table of values of the subentry of the compressibility factor. The table of values of the subentry of the compressibility factor in the Lee-Kesler equation is substituted into this program and the program can then directly select the corresponding $Z^{0}$ and $Z^{1}$ for calculation.

(3) Output of Program. We can choose to check the results of the formula calculation method and state equation method, respectively, or the maximum range based on the two methods (the union of two ranges). This optimization of 


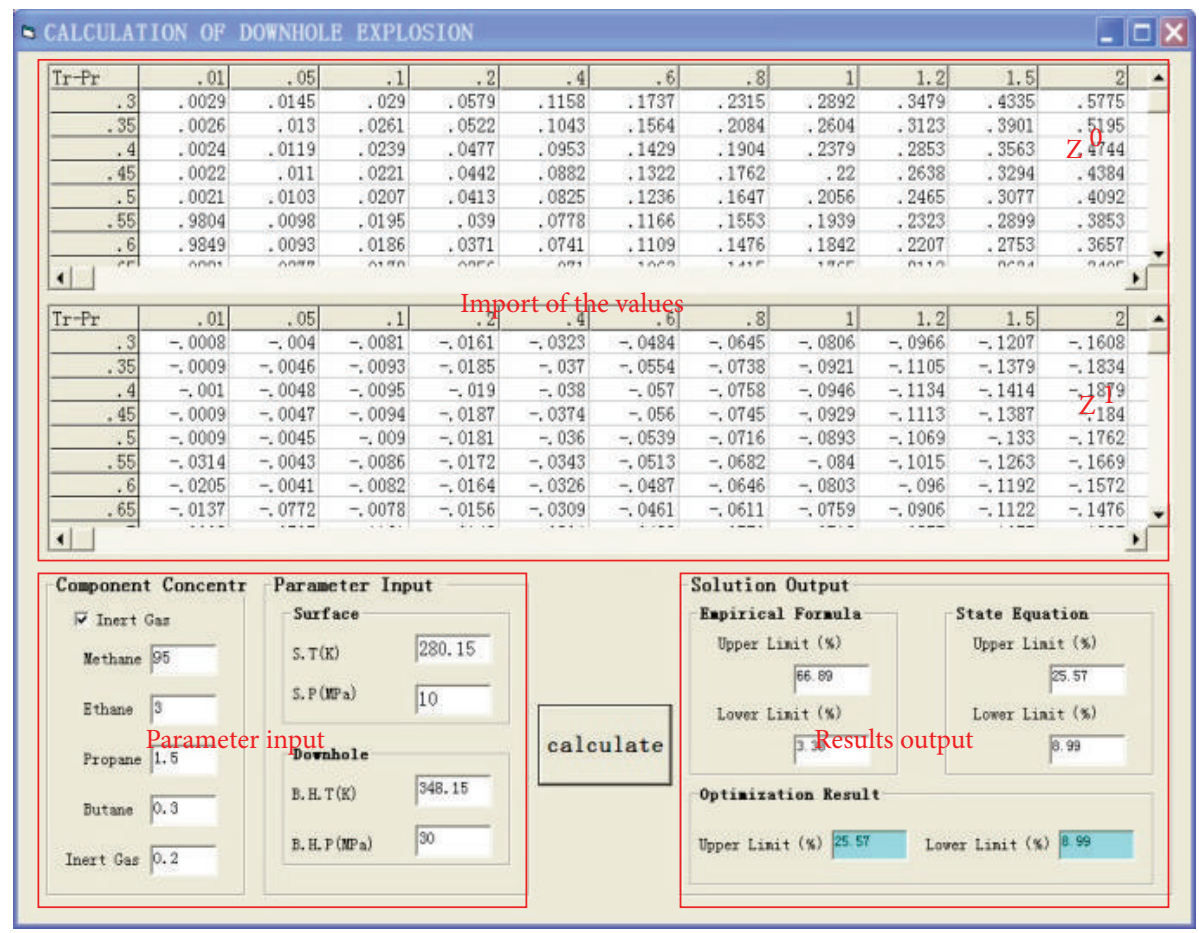

FIGURE 2: Software interface based on calculation model of explosive range in well.

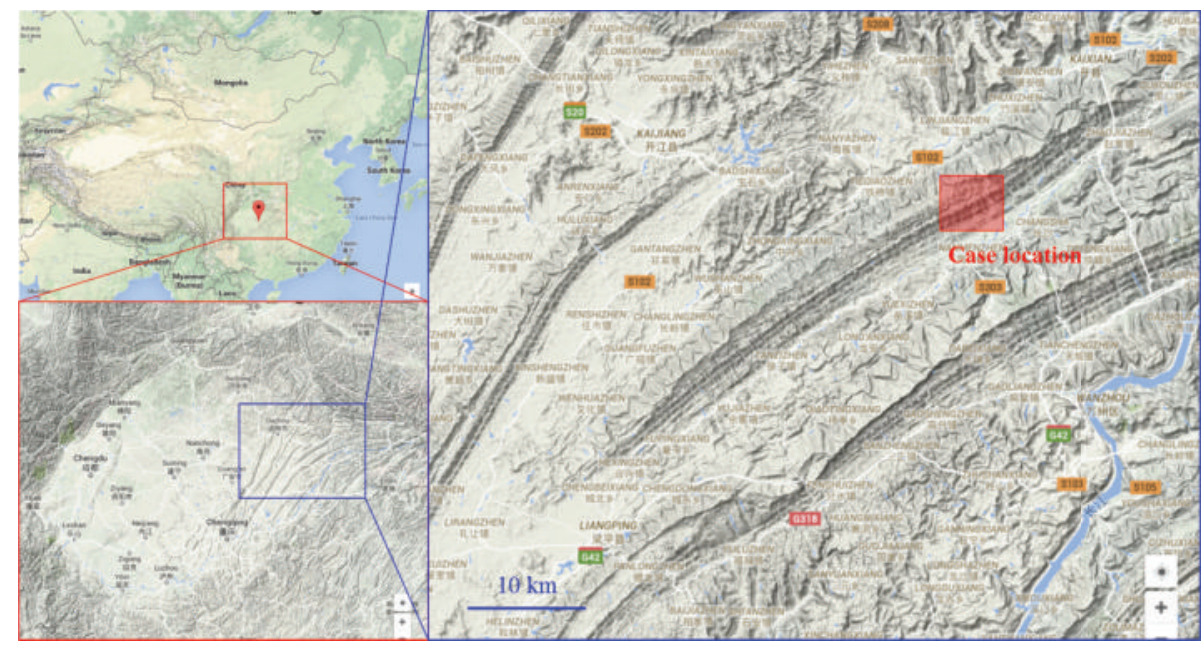

FIgURE 3: Tectonic map of the real case.

the explosive range using the maximum range makes the prediction more reliable.

\section{Application of Explosive Range Calculation Model}

3.1. Background of Case. A case in Chongqing, China, is used to validate the calculation model of explosion. The tectonic map is shown in Figure 3. The production of oil and gas in the upper well is frequent and intense and easily accompanied by water, which results in poor borehole wall stability. The local gas velocity is low, even to the point of stagnation, which can easily produce underground explosions. The designed depth of well (DM001) is $2700 \mathrm{~m}$ and the borehole diameter is $3.1 \mathrm{~m}$. Gas drilling is used at depths from 710 to $2200 \mathrm{~m}$. Using the explosive range model, the gas content and explosive range of DM001 are calculated in Table 2.

3.2. Model Prediction. In Table 2, four main gases, methane, ethane, propane, and butane, are used for calculation of the hydrocarbon value. The measured total hydrocarbon value means the percentage of the total value of the content of these four main gases in the total gas content in the well. When the total hydrocarbon value is in the explosive range, 
TABLE 2: Gas content and explosive range of DM001.

\begin{tabular}{|c|c|c|c|c|c|c|c|}
\hline \multirow{2}{*}{ Depth (m) } & \multicolumn{4}{|c|}{ Gas content from gas logging (\%) } & \multirow{2}{*}{$\begin{array}{c}\text { Explosive range calculated } \\
\text { by the model (\%) }\end{array}$} & \multirow{2}{*}{$\begin{array}{c}\text { Measured total hydrocarbon } \\
\text { value }(\%)\end{array}$} & \multirow{2}{*}{ Carbon dioxide (\%) } \\
\hline & Methane & Ethane & Propane & Butane & & & \\
\hline 2024.06 & 27.21 & 1.05 & 0.31 & 0.16 & $22.83-64.70$ & 4.78 & 2.31 \\
\hline 2025.23 & 31.78 & 1.23 & 0.87 & 0.58 & $18.80-54.16$ & 5.90 & 1.33 \\
\hline 2026.52 & 48.43 & 2.85 & 0.95 & 0.88 & $12.17-35.11$ & 7.82 & 2.54 \\
\hline 2027.11 & 59.39 & 4.62 & 1.75 & 1.28 & $9.44-27.70$ & 11.21 & 2.20 \\
\hline 2028.90 & 69.41 & 5.05 & 2.87 & 1.53 & $7.94-23.48$ & 14.32 & 2.94 \\
\hline 2029.39 & 87.61 & 6.74 & 3.04 & 2.10 & $6.34-18.67$ & 14.04 & 5.34 \\
\hline 2030.43 & 82.98 & 6.41 & 2.91 & 1.93 & $6.68-19.69$ & 15.88 & 3.12 \\
\hline 2030.98 & 85.01 & 6.51 & 2.82 & 1.95 & $6.56-19.28$ & 16.74 & 4.85 \\
\hline 2032.16 & 86.48 & 6.52 & 2.80 & 1.90 & $6.47-19.00$ & 16.19 & 7.36 \\
\hline 2033.15 & 84.25 & 6.48 & 2.75 & 1.82 & $6.62-19.47$ & 17.86 & 8.74 \\
\hline 2034.35 & 84.49 & 6.40 & 2.70 & 1.79 & $6.62-19.45$ & 17.45 & 9.34 \\
\hline 2034.71 & 87.70 & 6.91 & 3.20 & 2.18 & $6.29-18.57$ & 13.47 & 7.40 \\
\hline 2036.34 & 93.40 & 6.90 & 2.67 & 1.64 & $6.05-17.71$ & 20.97 & 11.45 \\
\hline 2038.31 & 87.93 & 6.72 & 3.09 & 2.11 & $6.31-18.60$ & 13.79 & 11.37 \\
\hline 2039.36 & 88.42 & 7.02 & 3.22 & 2.21 & $6.23-18.41$ & 12.34 & 12.48 \\
\hline 2039.86 & 88.95 & 6.66 & 3.03 & 2.05 & $6.27-18.44$ & 13.62 & 13.70 \\
\hline 2041.01 & 87.66 & 5.98 & 2.47 & 1.64 & $6.51-18.99$ & 19.24 & 15.78 \\
\hline 2042.83 & 87.03 & 5.91 & 2.48 & 1.71 & $6.55-19.13$ & 17.82 & 14.59 \\
\hline 2043.62 & 81.31 & 5.08 & 1.94 & 1.23 & $7.15-20.73$ & 20.07 & 16.58 \\
\hline
\end{tabular}

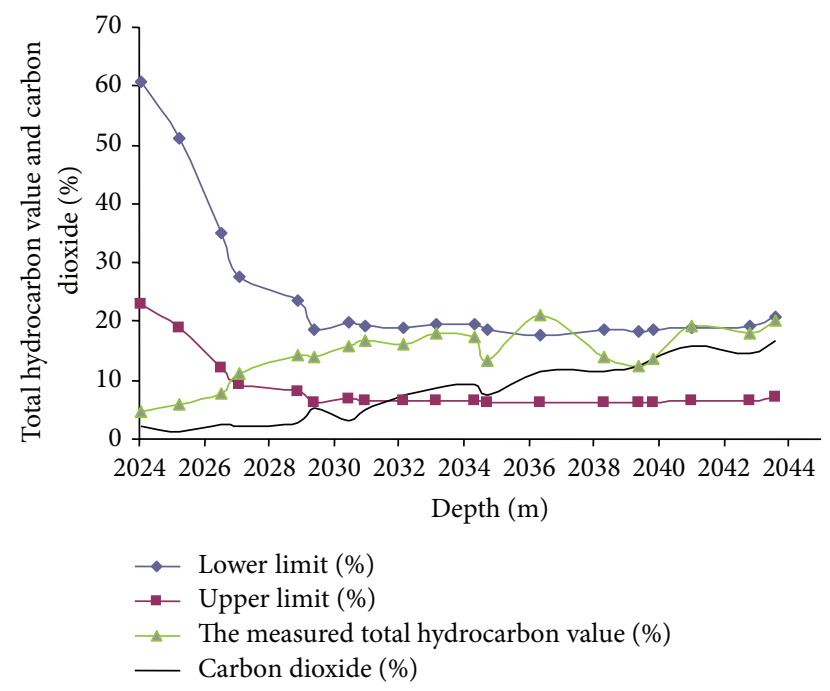

FIGURE 4: Analysis of results of calculation model and measurement.

an explosion may occur. The carbon dioxide value usually proves the phenomenon of explosion due to the increase of carbon dioxide after an explosion.

3.3. Validation of Model. Figure 4 makes clear that the total hydrocarbon value has an upward trend from 4.778 to $21.87 \%$ (from 2024-2043 m). This measurement is in the explosive range according to our model. Thus, the model makes a judgment of a probable explosion. The carbon dioxide monitoring data shows an upward trend after $2030 \mathrm{~m}$, which means a potential explosion consuming the $\mathrm{O}_{2}$ and increasing the $\mathrm{CO}_{2}$. In addition, a lot of carbide materials are found with the drill, providing evidence of the explosion phenomenon (Figure 5).

\section{Evolution of Influence Factors on Explosive Range}

In order to investigate the relations between the calculated explosive range and the inert gas content, temperature, and borehole gas pressure, we assumed the formation temperature $\left(75^{\circ} \mathrm{C}(348.15 \mathrm{~K})\right)$, pressure $(30 \mathrm{MPa})$, surface temperature $\left(7^{\circ} \mathrm{C}(280.15 \mathrm{~K})\right)$, borehole gas pressure $(10 \mathrm{MPa})$, and the content of methane, ethane, propane, butane, and inert gas as, respectively, $95,3,1.5,0.3$, and $0.2 \%$.

4.1. Influence of Inert Gas on the Explosive Range. According to the calculation model, when the content of inert gas is, respectively, $0.1,0.5,1.5,2,2.5$, and $3 \%$, the explosive range is as shown in Figure 6.

4.2. Influence of Temperature on the Explosive Range. With the increment of temperature, the explosive range predicted by the calculation model is as shown in Figure 7 (BHT: borehole temperature).

4.3. Influence of Gas Pressure on Explosive Range. With the increment of gas pressure, the explosive range predicted by the calculation model is as shown in Figure 8 (BHP: borehole gas pressure). 

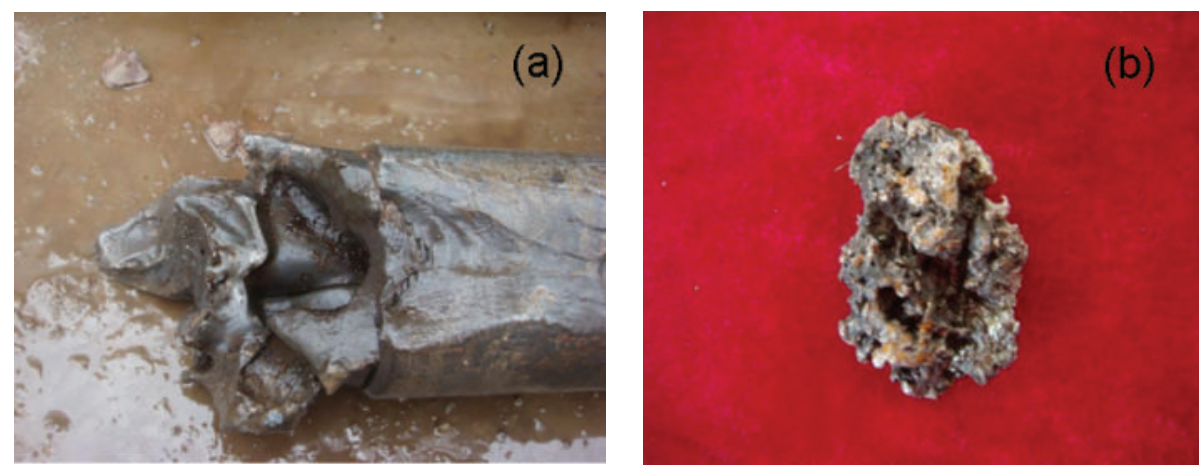

Figure 5: (a) Drill; (b) carbide material with drill after explosion.

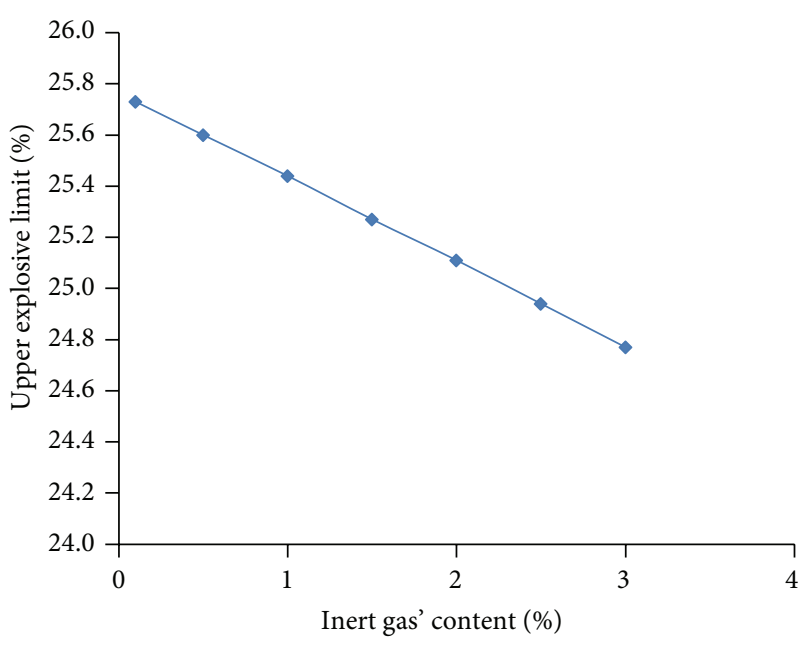

$\rightarrow$ Upper explosive limit (\%)

(a)

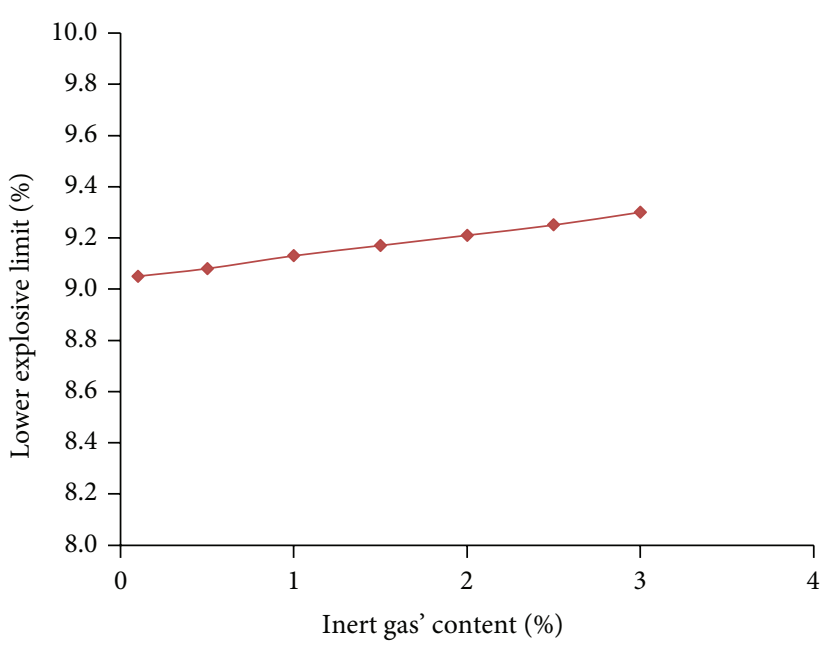

$\rightarrow$ Lower explosive limit (\%)

(b)

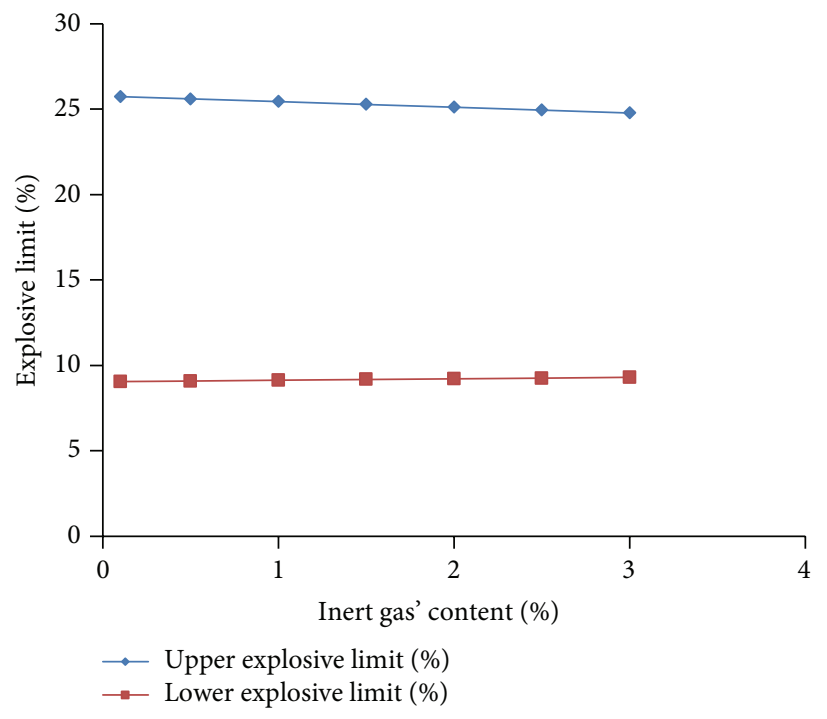

(c)

FIGURE 6: Relation between the explosive range and the content of inert gas: (a) upper explosive limit; (b) lower explosive limit; (c) explosive limit. 


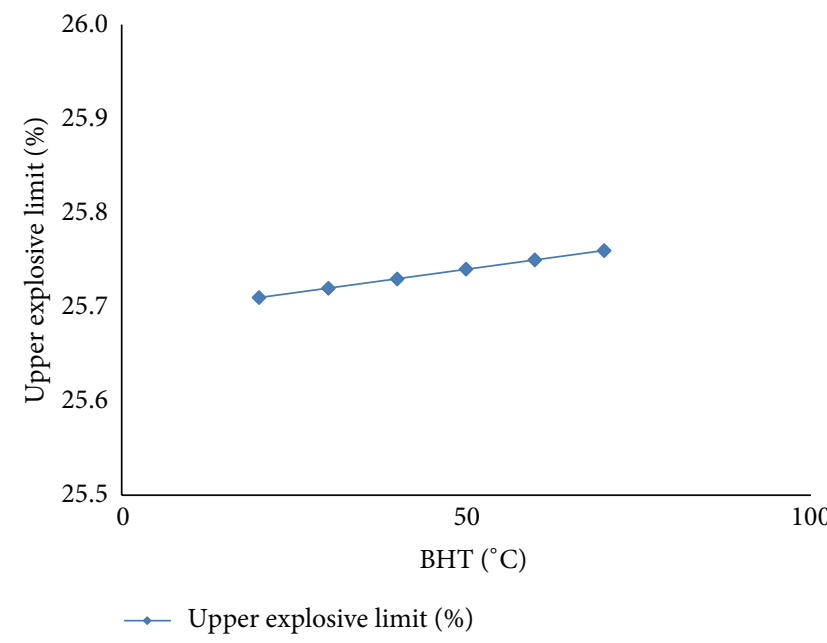

(a)

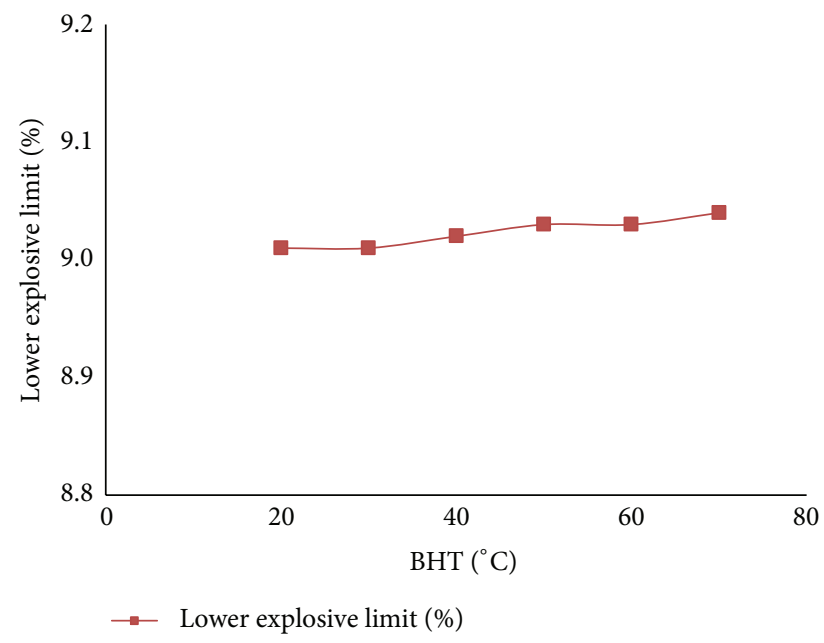

(b)

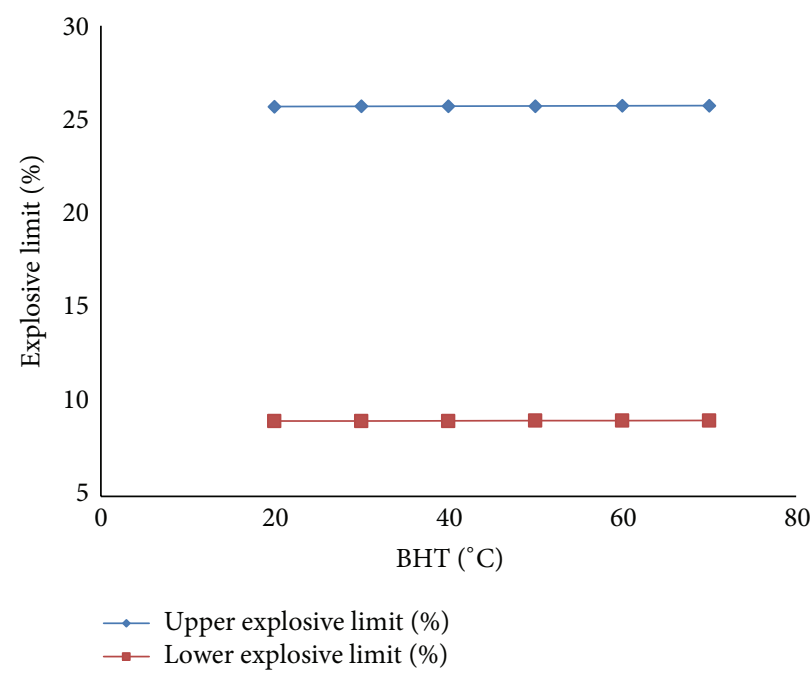

(c)

FIGURE 7: Relation between the explosive range and the temperature: (a) upper explosive limit; (b) lower explosive limit; (c) explosive limit.

All the results above remain the same as the theoretical law. (1) A higher content of inert gas induces a smaller possibility of explosion in the well. (2) A higher temperature means a bigger internal energy of the molecules. Thus, between molecules a higher speed of chemical reaction leads to a greater possibility of explosion. (3) A higher gas pressure shortens the distance between the molecules of the combustible gas, meaning a greater probability of bigger collisions between the molecules.

\section{Evaluation of Model}

5.1. Highlights. Considering the influence of temperature and pressure, our straightforward method is established to determine the explosive range of air drilling downhole by combining the state equation and the empirical formula method. The empirical formula method is convenient and effective but has a limited range of application; the state equation is a strict theoretical method but is time-consuming because of the complex calculation involved. The model can realize the calculation of the maximum range based on the two methods (the union of two ranges), which is more reliable for the prediction of explosive range. A case in Chongqing, China, validates the explosive range calculation model.

5.2. Limitations. For the empirical formula method, (1) is suitable when the ground temperature exceeds $100^{\circ} \mathrm{C}$, since at this time the influence of temperature on the explosion is obvious. Equation (2) is used only to calculate the explosive range of the gas mixture between normal gas pressure and $21 \mathrm{MPa}$. When calculating the inert gas content, the model does not consider the impact effect of every inert gas. Meanwhile, the combustible gas mixture just includes methane, ethane, propane, and butane.

\section{Conclusions}

Some valuable conclusions are as follows. (1) The explosive range in the well is mainly affected by the gas components, 


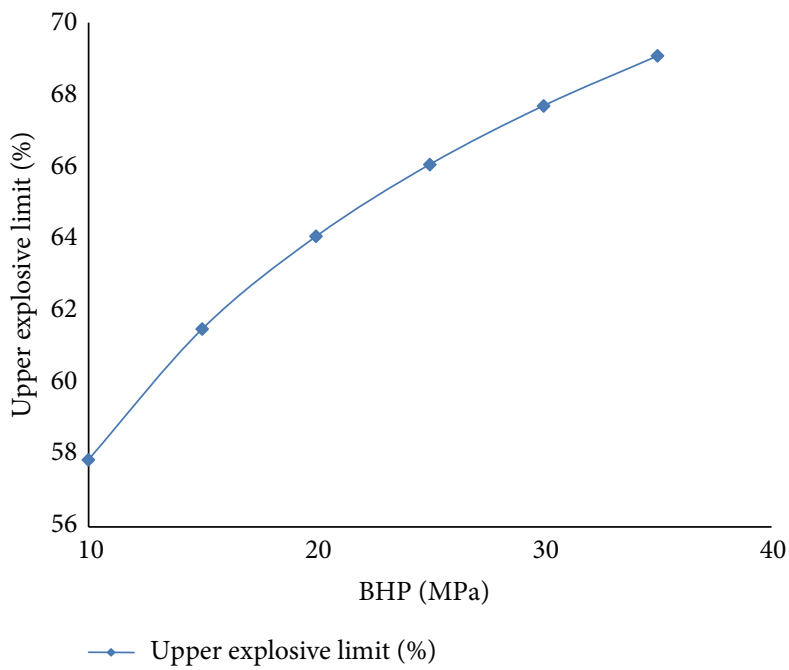

(a)

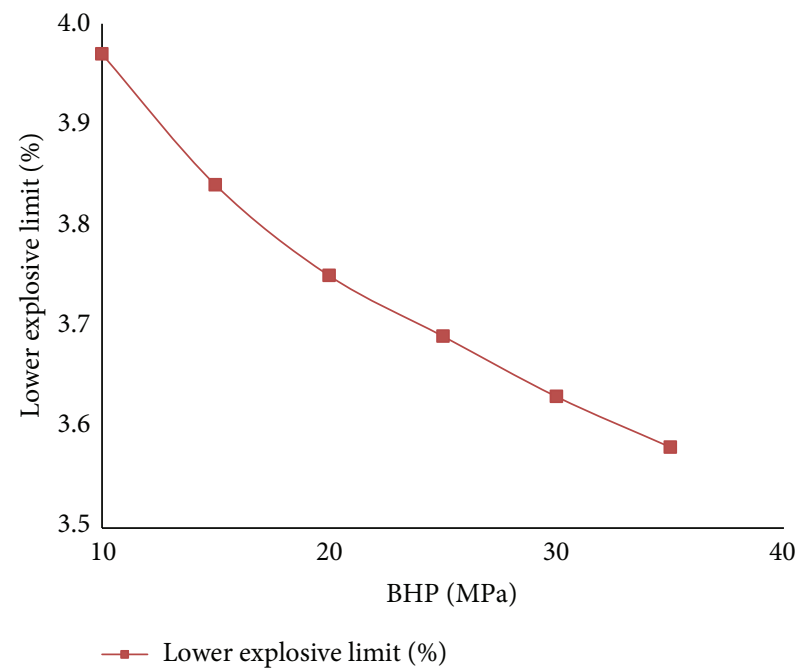

(b)

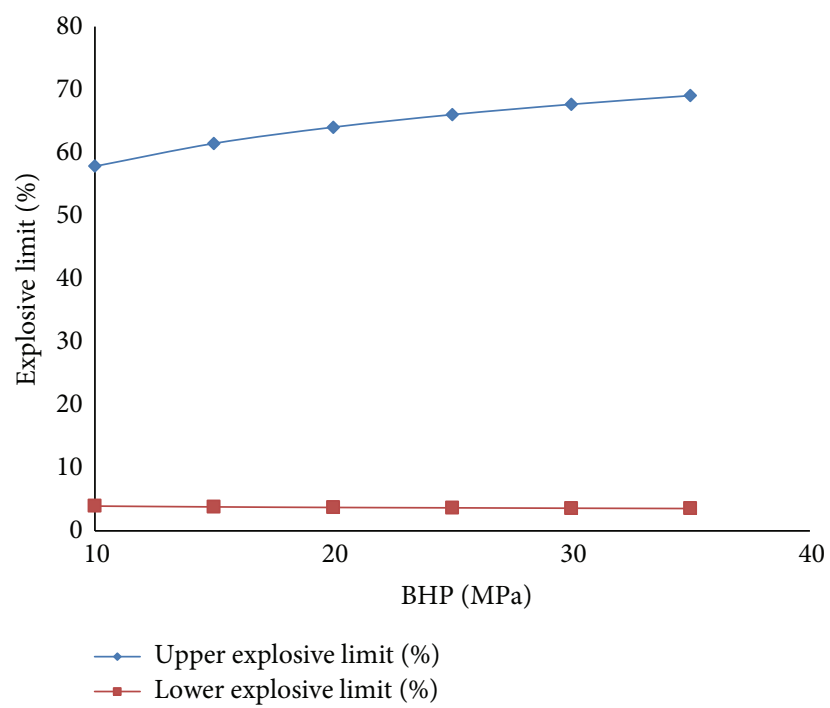

(c)

FiguRE 8: Relation between the explosive range and the pressure: (a) upper explosive limit; (b) lower explosive limit; (c) explosive limit.

inert gas, temperature, and pressure. (2) The calculation model based on combining the empirical formula and the state equation can increase the reliability of the estimation of the explosive range. (3) Increase of the inert gas content reduces the possibility of explosion, while high temperature and gas pressure improve the explosion probability.

\section{Nomenclature}

$L_{x}$ : Lower explosive limit of the single component, $\%$

$U_{x}$ : Upper explosive limit of the single component, \%

$n_{\mathrm{c}}$ : Carbon number in the chain hydrocarbon molecule, 1

$a_{1}$ : Empirical coefficient, 1

$a_{2}$ : Empirical coefficient, 1 $b_{1}$ : Empirical coefficient, 1

$b_{2}$ : Empirical coefficient, 1

$U_{h}$ : Upper limit of the gas mixture under normal pressure and temperature, $\%$

$L_{h}$ : Lower limit of the gas mixture under normal pressure and temperature, $\%$

$c_{i}$ : Concentration of individual gas in the gas mixture, $\%$

$U_{i}$ : Upper limit of individual gas, $\%$

$L_{i}$ : Lower limit of individual gas, $\%$

$n$ : The number of the single gas contained in the gas mixture, 1

$L_{m}$ : Lower explosive limit of the gas mixture when considering the inert gas, $\%$

$U_{m}$ : Upper explosive limit of the gas mixture when considering the inert gas, $\%$

$L_{h}$ : Lower explosive limit of the gas mixture when not considering the inert gas, $\%$ 
$U_{h}$ : Upper explosive limit of the gas mixture when not considering the inert gas, $\%$

$\alpha$ : $\quad$ Volume fraction of the inert gas, $\%$

$R: \quad 8.31 \mathrm{~J} / \mathrm{K} \cdot \mathrm{mol}$

$Z: \quad$ Compressibility factor, 1

$Z^{0}$ : Value of subentry of compressibility factor, 1

$Z^{1}$ : Value of subentry of compressibility factor, 1

$T_{r}$ : $\quad$ Reduced temperature, ${ }^{\circ} \mathrm{C}$

$P_{r}$ : $\quad$ Reduced gas pressure, $\mathrm{MPa}$

$T_{c}$ : Critical temperature of the air, ${ }^{\circ} \mathrm{C}$

$P_{c}$ : Critical pressure of the air, $\mathrm{MPa}$

$\omega$ : Acentric factor, 1

$T_{p c}$ : Cirtual critical temperature of the mixture, ${ }^{\circ} \mathrm{C}$

$P_{p c}$ : Virtual critical pressure of the mixture, $\mathrm{MPa}$

$T_{p r}$ : Virtual reduced temperature, ${ }^{\circ} \mathrm{C}$

$P_{p r}$ : Virtual reduced gas pressure, $\mathrm{MPa}$

$T_{c r x}$ : Critical temperature of individual gas, ${ }^{\circ} \mathrm{C}$

$P_{c r x}$ : Critical pressure of individual gas, $\mathrm{MPa}$

$\omega_{x}$ : The critical acentric factor of every single gas, 1

$y_{x}$ : $\quad$ Mole fraction of every single gas, 1

$P_{s}: \quad$ Ground gas pressure, $\mathrm{MPa}$

$P_{d}:$ Gas pressure in the shaft, $\mathrm{MPa}$

$V_{s}$ : Ground volume, $\mathrm{g} / \mathrm{cm}^{3}$

$V_{d}$ : Ground volume, volume in the shaft, $\mathrm{g} / \mathrm{cm}^{3}$

$Z^{s}$ : Compressibility factor of the ground, 1

$Z^{d}$ : Compressibility factor in the shaft, 1

$T_{s}$ : Temperature of the ground, ${ }^{\circ} \mathrm{C}$

$T_{d}$ : Temperature in the shaft, ${ }^{\circ} \mathrm{C}$

$L_{t}$ : $\quad$ Lower explosive limit at $t^{\circ} \mathrm{C}, \%$

$U_{t}$ : Upper explosive limit at $t^{\circ} \mathrm{C}, \%$

$U$ : Upper explosive limit at normal temperature $\left(25^{\circ} \mathrm{C}\right), \%$

$L$ : $\quad$ Lower explosive limit at normal temperature $\left(25^{\circ} \mathrm{C}\right), \%$

$t$ : $\quad$ Temperature of the combustible gas, ${ }^{\circ} \mathrm{C}$

$L_{p}$ : Lower explosive limit of the combustible gas under high pressure, $\%$

$U_{p}$ : Upper explosive limit of the combustible gas under high pressure, $\%$

$P: \quad$ Gas pressure at the bottom of well, MPa.

\section{Conflict of Interests}

The authors declare that there is no conflict of interests regarding the publication of this paper.

\section{Acknowledgments}

The research is supported by the National Natural Science Foundation of China (Grant no. 51474185), the National Key Basic Research and Development Program, (973 Program)
China (Grant no. 2013CB228003), and the China Postdoctoral Science Foundation (Grant no. 2014M560728).

\section{References}

[1] R. S. Carden, "Technology assessment of vertical and horizontal air drilling potential in the United States," Final Report, Grace Shursen Moore \& Associates, Amarillo, Tex, USA, 1993.

[2] L. W. Cooper, R. A. Hook, and B. R. Payne, "Air drilling techniques," in Proceedings of the SPE Deep Drilling and Production Symposium, SPE-6435-MS, Society of Petroleum Engineers, Amarillo, Tex, USA, April 1977.

[3] K. Bybee, "Air drilling in the presence of hydrocarbons: a time for pause," Journal of Petroleum Technology, vol. 59, no. 11, pp. 86-87, 2007.

[4] S. A. Mehta, R. G. Moore, C. J. Laureshen, P. Samuel, R. Teichrob, and D. Bennion, "Safety considerations for underbalanced drilling of horizontal wells using air or oxygencontaining gas," Journal of Canadian Petroleum Technology, vol. 37, no. 9, 2013.

[5] B. Lewis and G. Von Elbe, Combustion, Flames and Explosions of Gases, Elsevier, 2012.

[6] B. Vanderstraeten, D. Tuerlinckx, J. Berghmans, S. Vliegen, E. V. Oost, and B. Smit, "Experimental study of the pressure and temperature dependence on the upper flammability limit of methane/air mixtures," Journal of Hazardous Materials, vol. 56, no. 3, pp. 237-246, 1997.

[7] K. Shahbazi, S. A. Mehta, R. G. Moore, M. G. Ursenbach, and K. C. Van Fraassen, "Investigation of explosion occurrence in underbalanced drilling," in Proceedings of the Production and Operations Symposium, Society of Petroleum Engineers, Oklahoma City, Okla, USA, March-April 2007.

[8] D. Bjerketvedt, J. R. Bakke, and K. Van Wingerden, "Gas explosion handbook," Journal of Hazardous Materials, vol. 52, no. 1, pp. 1-150, 1997.

[9] M. Vidal, W. J. Rogers, J. C. Hoiste, and M. S. Mannan, "A review of estimation methods for flash points and flammability limits," Process Safety Progress, vol. 23, no. 1, pp. 47-55, 2004.

[10] L. Zhang, "Analysis of downhole explosion in gas drilling," Journal of Southwest Petroleum University (Science \& Technology Edition), vol. 34, no. 5, pp. 146-152, 2012.

[11] K. P. Malloy, G. H. Medley, and R. Stone, "Air drilling in the presence of hydrocarbons: a time for pause," in Proceedings of the IADC/SPE Managed pressure Drilling and Underbalanced Operations Conference and Exhibition, SPE-108357-MS, Society of Petroleum Engineers, Galveston, Tex, USA, March 2007.

[12] Y. Li, The analysis of blasting and burning of air atomized drilling well [Dissertation for Engineering Master Degree], Chongqing University, Chongqing, China, 2002.

[13] J. M. Prausnitz, R. N. Lichtenthaler, and E. G. de Azevedo, Molecular Thermodynamics of Fluid-Phase Equilibria, Pearson Education, 1998.

[14] C. K. Law and F. N. Egolfopoulos, "A kinetic criterion of flammability limits: the CHO-inert system," Symposium (International) on Combustion, vol. 23, no. 1, pp. 413-421, 1991.

[15] J. D. Kiper, E. Howard, and C. Ames, "Criteria for evaluation of visual programming languages," Journal of Visual Languages \& Computing, vol. 8, no. 2, pp. 175-192, 1997. 


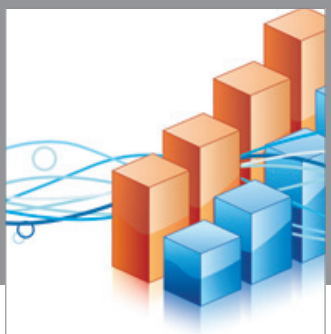

Advances in

Operations Research

vatem alat4

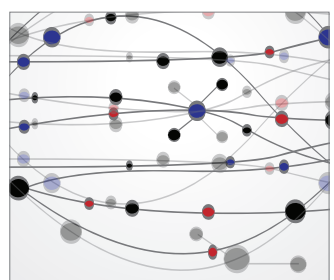

\section{The Scientific} World Journal
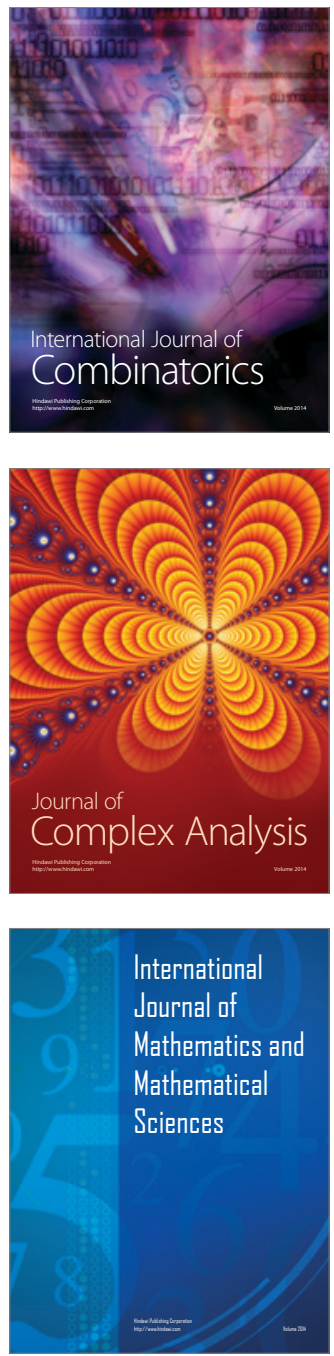
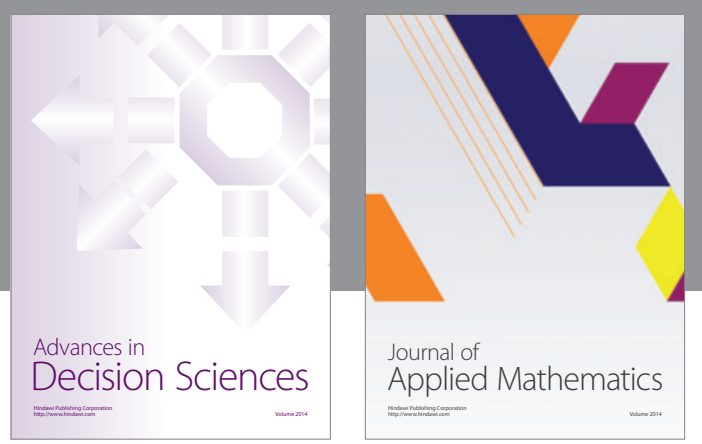

Algebra

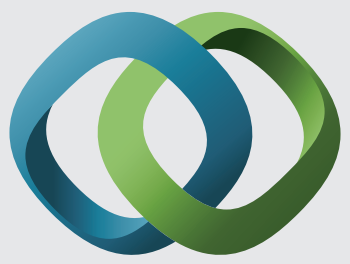

\section{Hindawi}

Submit your manuscripts at

http://www.hindawi.com
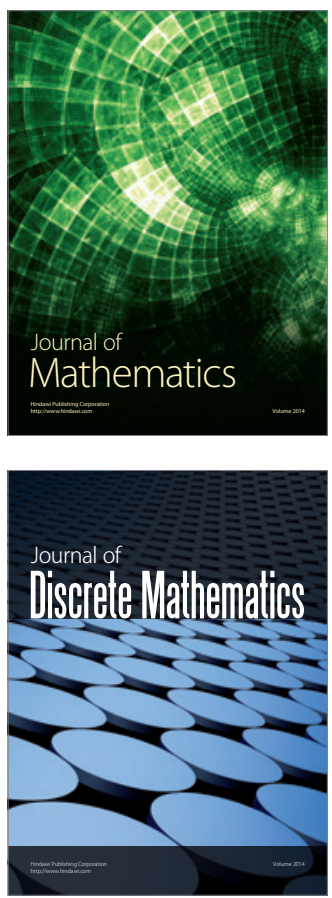

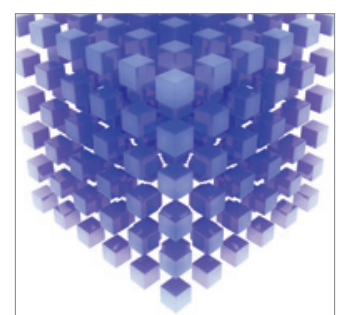

Mathematical Problems in Engineering
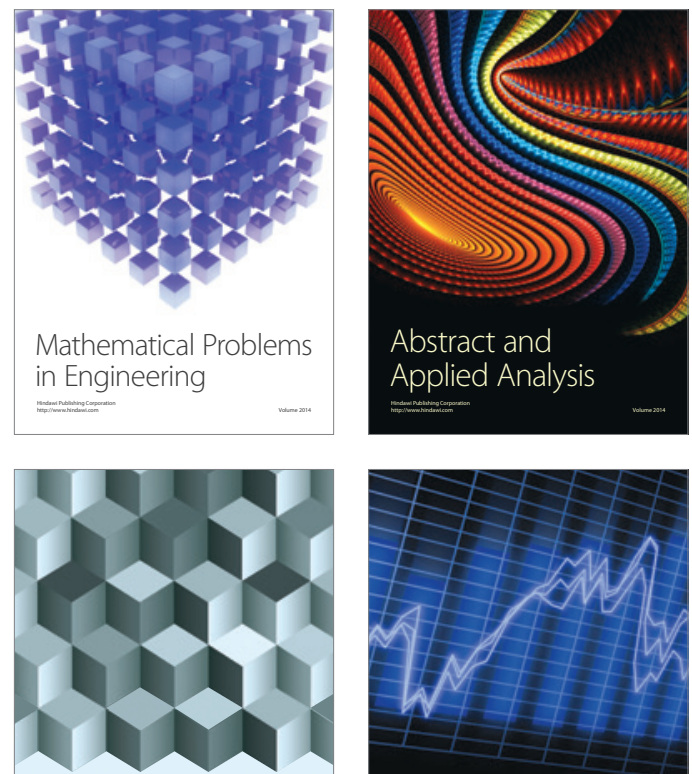

Journal of

Function Spaces

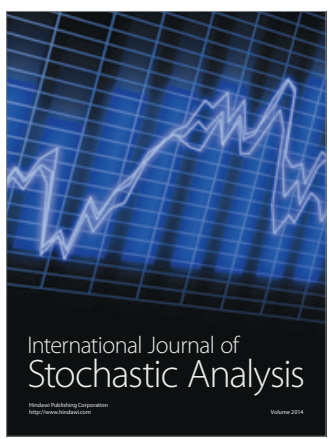

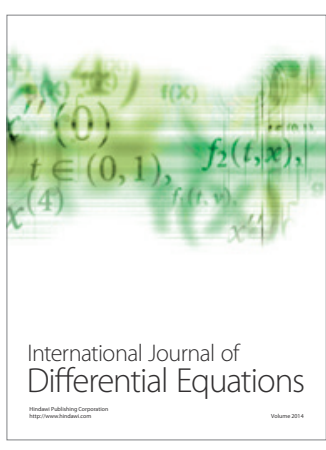
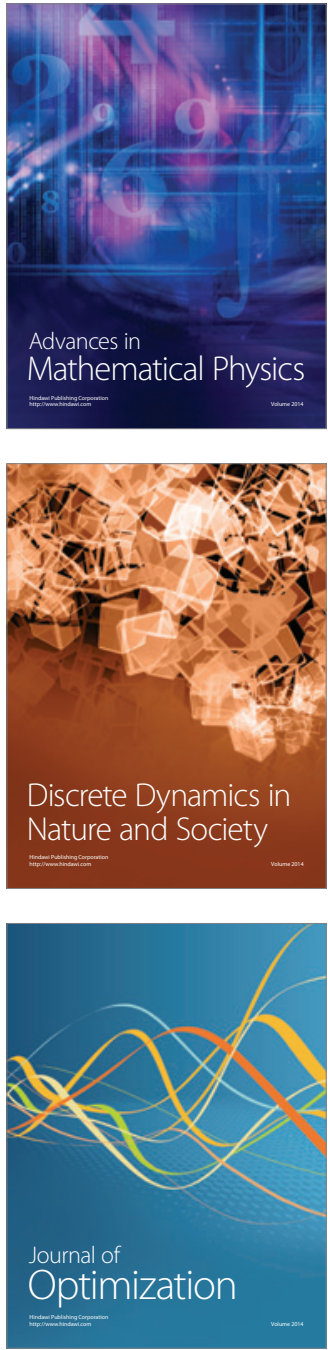